\title{
Mechanistic Investigation of DBU-Based Ionic Liquids for Aza-Michael Reaction: Mass Spectrometry and DFT Studies of Catalyst Role
}

\author{
Augusto A. Cândido, ${ }^{a}$ Thiago C. Rozada, ${ }^{b}$ Andrew M. F. Rozada, ${ }^{a}$ João R. B. Souza, ${ }^{a}$ \\ Eduardo J. Pilau, ${ }^{\circledR a}$ Fernanda A. Rosa, ${ }^{a}$ Ernani A. Basso ${ }^{\circledR a}$ and Gisele F. Gauze ${ }^{\circledR} * a$ \\ ${ }^{a}$ Departamento de Química, Universidade Estadual de Maringá, 87020-900 Maringá-PR, Brazil \\ ${ }^{b}$ Departamento de Química, Universidade Estadual de Ponta Grossa, 84030-900 Ponta Grossa-PR, Brazil
}

\begin{abstract}
1,8-Diazabicyclo[5.4.0]undec-7-ene (DBU)-based ionic liquids (ILs) has exhibited a high catalytic activity in the aza-Michael reactions compared to conventional catalysts and with imidazole-based ILs. In the present work DBU-based ILs showed high catalytic potential for aza-Michael addition of aromatic amines to 2-cyclohexen-1-one under solvent-free condition. Electrospray ionization-mass spectrometry (ESI-MS) and density functional theory studies have been carried out to provide an effective activation mode of DBU-based ILs in aza-Michael addition. Our results show that both the presence of the acid hydrogen in the IL and the ability of the anion to carry out a hydrogen bond with the $-\mathrm{NH}_{2}$ group of the arylamine are fundamental for the reaction catalysis. The catalytic model proposed can be used for the rational development of new ILs with excellent catalytic properties.
\end{abstract}

Keywords: conjugate addition, aromatic amines, reaction mechanism, theoretical calculations, ESI-MS studies

\section{Introduction}

The aza-Michael additions can be used for $\mathrm{C}-\mathrm{N}$ bond formation by the reaction of $\alpha, \beta$-unsaturated carbonyl compounds with amines. The products $\beta$-aminocarbonylic are important intermediates for the synthesis of $\beta$-aminoalcohol, $\beta$-amino acid derivatives, and $\beta$-aminocarbamates, that are bioactive compounds. ${ }^{1-4}$

It was usually catalyzed by strong base or a Lewis acid, ultrasound, heterogeneous solid acid, ionic amino acids, etc. ${ }^{5-11}$ However, there are still many deficiencies of these catalysts mentioned above, such as the requirement of long reaction time, harsh reaction conditions, many side reactions and mainly most of the reported methods ${ }^{12-15}$ are successful only with aliphatic amines and lead to low conversions for aromatic amines.

Toward this directive, the organocatalytic ionic liquids (ILs) has shown to be efficient in promoting the aza-Michael addition. ${ }^{16-22}$ Notably, 1,8-diazabicyclo[5.4.0]undec-7-ene (DBU)-based ILs has exhibited a high catalytic activity in the aza-Michael reactions compared to conventional catalysts and with imidazole-based ILs. ${ }^{1,23-27}$ However, the

*e-mail: gfgbandoch@uem.br effective role of catalysis by DBU-based ILs has not been completely investigated and to know the catalytic model is very important for designing and developing ionic liquids with excellent catalytic properties.

In this work, we evaluated the catalytic efficiency of DBU-based ILs (Scheme 1) by mass spectrometry (MS) and density functional theory (DFT) studies to provide a catalytic model in aza-Michael additions. For a better mechanistic understanding of aza-Michael IL-catalyzed reaction, a few questions need to be addressed: $(i)$ the real role of the protic cation in the title reaction, DBU-based ILs with aprotic cation can also activate the substrate?; (ii) what is the effective function of the anion in the reaction? Accordingly, our results will provide important basis into the DBU-based IL activation mode and can be used to rational design of new organocatalysts.

\section{Experimental}

${ }^{1} \mathrm{H}$ and ${ }^{13} \mathrm{C}$ nuclear magnetic resonance (NMR) were recorded on a Bruker Avance III HD spectrometer operating at $500 \mathrm{MHz}$ for ${ }^{1} \mathrm{H}$ and $125 \mathrm{MHz}$ for ${ }^{13} \mathrm{C}$ in $\mathrm{D}_{2} \mathrm{O}$ and $\mathrm{CDCl}_{3}$. Chemical shifts $(\delta)$ were reported in parts per million (ppm), relative to the internal standard of 2,2-dimethyl- 


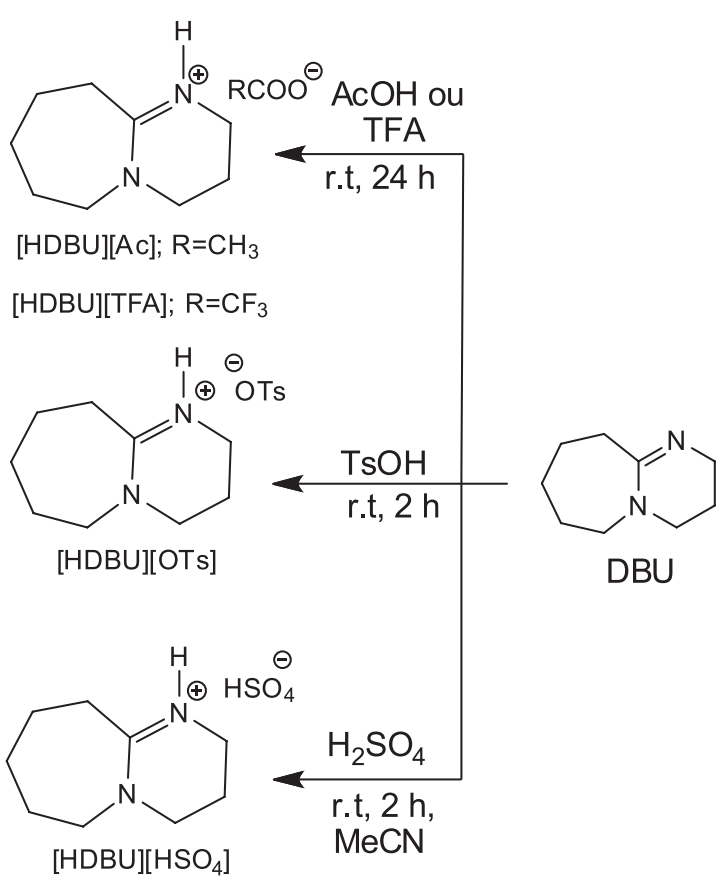

Scheme 1. Synthesis of the DBU-based ILs and their structures.

2-silapentane-5-sulfonate (DSS). Mass spectrometry data were obtained on Impact II, Bruker Daltonics Corporation, Germany, using electrospray ionization source (ESI) positive mode.

[HDBU][Ac], [HDBU][TFA] and [HDBU][OTs], TFA: trifluoroacetate, were obtained according to procedures previously described in the literature. ${ }^{24,28}$ ILs and Michael adducts were characterized by NMR analysis.

General procedure for preparation of ionic liquid [HDBU] $\left[\mathrm{HSO}_{4}\right]$ and [HDBU][Br]

DBU $(1.5 \mathrm{~mL}, 10 \mathrm{mmol})$ and acetonitrile $(3 \mathrm{~mL})$ were charged into a $25 \mathrm{~mL}$ round-bottom flask. Then, the mixture was taken at $0{ }^{\circ} \mathrm{C}$ and $98 \% \mathrm{H}_{2} \mathrm{SO}_{4}(0.6 \mathrm{~mL}, 10 \mathrm{mmol})$ or $48 \% \mathrm{HBr}(1.1 \mathrm{~mL}, 20 \mathrm{mmol})$ was added dropwise keeping the temperature at $0-5{ }^{\circ} \mathrm{C}$. After addition, the mixture was stirred for $2 \mathrm{~h}$ at room temperature. The solution was washed repeatedly with ether $(3 \times 5 \mathrm{~mL})$ to remove non-ionic residues and the oil residues was dried in vacuum at $60{ }^{\circ} \mathrm{C}$ for $12 \mathrm{~h}$ to afford desired ionic liquids as light yellow viscous liquids.

\section{$[\mathrm{HDBU}]\left[\mathrm{HSO}_{4}\right]$}

${ }^{1} \mathrm{H}$ NMR (500 MHz, $\left.\mathrm{D}_{2} \mathrm{O}\right) \delta 3.52-3.50$ (m, 2H, H9), 3.48-3.45 (m, 2H, H11), 3.28-3.25 (m, 2H, H2), 2.58-2.56 (m, 2H, H6), 1.98-1.93 (m, 2H, H10), 1.71-1.62 (m, 6H, $\mathrm{H} 3, \mathrm{H} 4, \mathrm{H} 5) ;{ }^{13} \mathrm{C} \mathrm{NMR}\left(125 \mathrm{MHz}, \mathrm{D}_{2} \mathrm{O}\right) \delta 165.9,54.1$, 48.2, 37.9, 32.7, 28.4, 25.8, 23.3, 18.7.

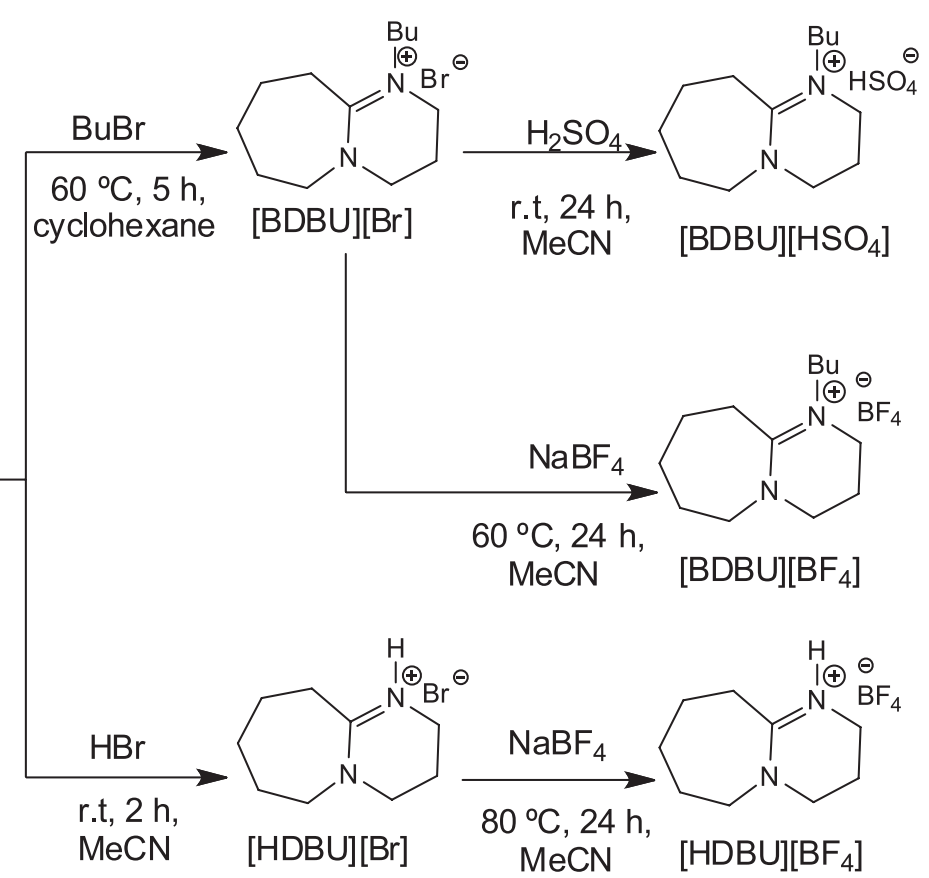

[HDBU][Br]

${ }^{1} \mathrm{H}$ NMR (500 MHz, $\left.\mathrm{D}_{2} \mathrm{O}\right) \delta 3.58-3.56$ (m, 2H, H9), 3.54-3.52 (m, 2H, H11), 3.34-3.31 (m, 2H, H2), 2.64-2.52 (m, 2H, H6), 2.04-1.99 (m, 2H, H10), 1.76-1.66 (m, 6H, $\mathrm{H} 3, \mathrm{H} 4, \mathrm{H} 5) ;{ }^{13} \mathrm{C}$ NMR (125 MHz, $\left.\mathrm{D}_{2} \mathrm{O}\right) \delta 165.9,54.2$, 48.2, 38.0, 32.7, 28.4, 25.9, 23.3, 18.9.

General procedure for preparation of ionic liquid [HDBU] $\left[\mathrm{BF}_{4}\right]$

[HDBU][Br] (1.4 g, $6 \mathrm{mmol})$ and acetonitrile $(5 \mathrm{~mL})$ were charged into a $25 \mathrm{~mL}$ round-bottom flask. Then, $\mathrm{NaBF}_{4}(0.7 \mathrm{~g}, 6 \mathrm{mmol})$ was added and the mixture was stirred for $24 \mathrm{~h}$ at $80{ }^{\circ} \mathrm{C}$. The solution was filtred to remove $\mathrm{NaBr}$ and the solid was washed repeatedly with dichloromethane. The solvent was removed under reduced pressure and oil residues was dried in vacuum at $60{ }^{\circ} \mathrm{C}$ for $12 \mathrm{~h}$ to afford a light yellow viscous liquid.

${ }^{1} \mathrm{H}$ NMR (500 MHz, D $\left.2 \mathrm{O}\right) \delta 3.58-3.56$ (m, 2H, H9), 3.55-3.52 (m, 2H, H11), 3.34-3.32 (m, 2H, H2), 2.64-2.62 (m, 2H, H6), 2.05-2.00 (m, 2H, H10), 1.77-1.68 (m, 6H, $\mathrm{H} 3, \mathrm{H} 4, \mathrm{H} 5) ;{ }^{13} \mathrm{C}$ NMR (125 MHz, $\left.\mathrm{D}_{2} \mathrm{O}\right) \delta 165.9$, 54.1, 48.2, 38.0, 32.8, 28.5, 23.3, 18.9 .

\section{General procedure for preparation of [BDBU][Br]}

DBU (1.5 mL, $10 \mathrm{mmol})$ and cyclohexane $(5 \mathrm{~mL})$ were charged into a $25 \mathrm{~mL}$ round-bottom flask. Then, bromobutane $(1.2 \mathrm{~mL}, 17 \mathrm{mmol})$ was added for $1 \mathrm{~h}$ at room temperature and stirred for another $5 \mathrm{~h}$ at $60^{\circ} \mathrm{C}$. [BDBU][Br] 
precipitated as pale-yellow solid that was separated from the solvent by filtration, washed four times with ethyl acetate and dried in vacuum at $60{ }^{\circ} \mathrm{C}$ for $12 \mathrm{~h}$.

${ }^{1} \mathrm{H}$ NMR $\left(500 \mathrm{MHz}, \mathrm{D}_{2} \mathrm{O}\right) \delta 3.60-3.58\left(2 \mathrm{H}, \mathrm{m}, \mathrm{CH}_{2}\right)$, 3.51-3.45 (m, 6H, H9, H11, H2), 2.83-2.81 (m, 2H, H6), 2.06-1.99 (m, 2H, H10), 1.76-1.66 (m, 6H, H3, H4, H5), 1.63-1.57 (m, $\left.2 \mathrm{H}, \mathrm{CH}_{2}\right), 1.36-1.28\left(\mathrm{~m}, 2 \mathrm{H}, \mathrm{CH}_{2}\right), 0.91(\mathrm{t}$, $\left.3 \mathrm{H}, \mathrm{CH}_{3}, J 7.4 \mathrm{~Hz}\right) ;{ }^{13} \mathrm{C}$ NMR $\left(125 \mathrm{MHz}, \mathrm{D}_{2} \mathrm{O}\right) \delta 166.4$, 54.6, 53.4, 48.8, 46.9, 30.2, 28.1, 27.8, 25.6, 22.8, 19.8, 13.1.

General procedure for preparation of ionic liquid $[\mathrm{BDBU}]\left[\mathrm{HSO}_{4}\right]$

[BDBU] $[\mathrm{Br}](2.9 \mathrm{~g}, 10 \mathrm{mmol})$ and acetonitrile $(5 \mathrm{~mL})$ were charged into a $25 \mathrm{~mL}$ round-bottom flask. Then, $98 \% \mathrm{H}_{2} \mathrm{SO}_{4}(0.6 \mathrm{~mL}, 10 \mathrm{mmol})$ was added dropwise at room temperature. The mixture was purged with nitrogen gas for $24 \mathrm{~h}$ to remove $\mathrm{HBr}$ from the system. The solvent was removed under reduced pressure and oil residues was washed with hexane and dried in vacuum at $60^{\circ} \mathrm{C}$ for $12 \mathrm{~h}$ to afford a light yellow viscous liquid.

${ }^{1} \mathrm{H}$ NMR $\left(500 \mathrm{MHz}, \mathrm{D}_{2} \mathrm{O}\right) \delta$ 3.57-3.55 (m, 2H, $\left.\mathrm{CH}_{2}\right)$, 3.48-3.41 (m, 6H, H2, H9, H11), 2.80-2.78 (m, 2H, H6), 2.03-1.96 (m, 2H, H10), 1.73-1.63 (m, 6H, H3, H4, H5), $1.60-1.54\left(\mathrm{~m}, 2 \mathrm{H}, \mathrm{CH}_{2}\right), 1.33-1.25\left(\mathrm{~m}, 2 \mathrm{H}, \mathrm{CH}_{2}\right), 0.88(\mathrm{t}, 3 \mathrm{H}$, $\left.\mathrm{CH}_{3}, J 7.4 \mathrm{~Hz}\right) ;{ }^{13} \mathrm{C}$ NMR $\left(125 \mathrm{MHz}, \mathrm{D}_{2} \mathrm{O}\right) \delta 166.4,54.6$, $53.3,48.8,46.9,30.1,28.1,27.7,25.6,22.8,19.7,19.2,13.1$.

General procedure for preparation of ionic liquid $[\mathrm{BDBU}]\left[\mathrm{BF}_{4}\right]$

[BDBU][Br] $(1.4 \mathrm{~g}, 6 \mathrm{mmol})$ and acetonitrile $(3 \mathrm{~mL})$ were charged into a $25 \mathrm{~mL}$ round-bottom flask. Then, $\mathrm{NaBF}_{4}(0.7 \mathrm{~g}, 6 \mathrm{mmol})$ was added and was stirred for $24 \mathrm{~h}$ at $60{ }^{\circ} \mathrm{C}$. The solution was filtred to remove $\mathrm{NaBr}$ and the solid was washed repeatedly with dichloromethane. The solvent was removed under reduced pressure and oil residues was dried in vacuum at $60{ }^{\circ} \mathrm{C}$ for $12 \mathrm{~h}$ to afford a dark yellow viscous liquid.

${ }^{1} \mathrm{H}$ NMR $\left(500 \mathrm{MHz}, \mathrm{D}_{2} \mathrm{O}\right) \delta$ 3.66-3.64 (m, 2H, $\left.\mathrm{CH}_{2}\right)$, 3.58-3.50 (m, 6H, H2, H9, H11), 2.88-2.86 (m, 2H, H6), 2.12-2.04 (m, 2H, H10), 1.81-1.72 (m, 6H, H3, H4, H5), 1.69-1.63 (m, 2H, CH $\left.3 \mathrm{H}, \mathrm{CH}_{3}, J 7.3 \mathrm{~Hz}\right) ;{ }^{13} \mathrm{C}$ NMR $\left(125 \mathrm{MHz}, \mathrm{D}_{2} \mathrm{O}\right) \delta 166.3$, 54.5, 53.3, 48.7, 46.8, 30.1, 28.1, 27.6, 25.5, 22.7, 19.6, 19.2, 13.0.

General procedure for aza-Michael reaction of aromatic amines with cycloexen-2-one

To a mixture of the aromatic amine $(1 \mathrm{mmol})$ and cycloexen-2-one (1 mmol) in $25 \mathrm{~mL}$ flask equipped with a magnetic stirrer, ionic liquid was added ( 0.3 equiv.). The reaction mixture was stirred at room temperature for the desired time. Upon completion of the reaction, the mixture was diluted with water $\left(\mathrm{H}_{2} \mathrm{O}, 3 \mathrm{~mL}\right)$ and extracted with ethyl acetate $(3 \times 5 \mathrm{~mL})$. The combined organic phase was concentrated through vacuum evaporation and the resulting crude product was analyzed by ${ }^{1} \mathrm{H}$ NMR. The ionic liquid after extraction was dried in vacuo at $60{ }^{\circ} \mathrm{C}$ for $5 \mathrm{~h}$. The recovered ionic liquid was then reused in subsequent reactions.

\section{3-Phenylamino-cyclohexan-1-one (3a)}

${ }^{1} \mathrm{H}$ NMR $\left(500 \mathrm{MHz}, \mathrm{CDCl}_{3}\right) \delta$ 7.19-7.15 (m, 2H), 6.74$6.72(\mathrm{~m}, 1 \mathrm{H}), 6.61-6.59(\mathrm{~m}, 2 \mathrm{H}), 3.81-3.76(\mathrm{~m}, 1 \mathrm{H}), 3.59$ (sl, 1H), $2.84(\mathrm{dd}, 1 \mathrm{H}, J 14.4,6.0 \mathrm{~Hz}), 2.40-2.36(\mathrm{~m}, 2 \mathrm{H})$, 2.29-2.25 (m, 1H), 2.20-2.16 (m, 1H), 2.08-2.03 (m, 1H), $1.78-1.74(\mathrm{~m}, 1 \mathrm{H}), 1.72-1.70(\mathrm{~m}, 1 \mathrm{H})$.

3-(4-Nitro)phenylamino-cyclohexan-1-one (3b)

${ }^{1} \mathrm{H} \mathrm{NMR}\left(500 \mathrm{MHz}, \mathrm{CDCl}_{3}\right) \delta 8.08(\mathrm{~d}, 2 \mathrm{H}, J 9.2 \mathrm{~Hz})$, $6.55(\mathrm{~d}, 2 \mathrm{H}, J 9.2 \mathrm{~Hz}), 4.71(\mathrm{sl}, 1 \mathrm{H}), 3.93-3.89(\mathrm{~m}, 1 \mathrm{H})$, 2.87-2.82 (m, 1H), 2.43-2.36 (m, 3H), 2.24-2.20 (m, 1H), 2.12-2.08 (m, 1H), 1.84-1.77 (m, 2H).

3-(2-Nitro)phenylamino-cyclohexan-1-one (3c)

${ }^{1} \mathrm{H}$ NMR $\left(500 \mathrm{MHz}, \mathrm{CDCl}_{3}\right) \delta 8.17-8.15$ (dd, $1 \mathrm{H}, J$ 8.6, $1.6 \mathrm{~Hz}), 7.46-7.42(\mathrm{~m}, 1 \mathrm{H}), 6.85-6.83(\mathrm{~d}, 1 \mathrm{H}, J 8.6 \mathrm{~Hz})$, 6.69-6.67 (m, 1H), 3.99-3.64 (m, 1H), 2.89-2.84 (m, 1H), $2.48-2.39(\mathrm{~m}, 3 \mathrm{H}), 2.32-2.17(\mathrm{~m}, 1 \mathrm{H}), 2.16-2.11(\mathrm{~m}, 1 \mathrm{H})$, $1.87-1.77(\mathrm{~m}, 2 \mathrm{H})$.

3-(3-Nitro)phenylamino-cyclohexan-1-one (3d)

${ }^{1} \mathrm{H} \mathrm{NMR}\left(500 \mathrm{MHz}, \mathrm{CDCl}_{3}\right) \delta 7.55$ (ddd, $1 \mathrm{H}, J$ 8.1, 2.2, $0.9 \mathrm{~Hz}), 7.40$ (t, 1H, J 2.2 Hz), 7.29-7.28 (m, 1H), 6.88-6.86 (ddd, $1 \mathrm{H}, J 8.1,2.2,0.9 \mathrm{~Hz}), 3.92-3.87(\mathrm{~m}, 1 \mathrm{H}), 2.88-2.83$ (m, 1H), 2.41-2.35 (m, 3H), 2.25-2.20 (m, 1H), 2.12-2.06 (m, 1H), 1.86-1.76 (m, 2H).

\section{3-(2-Fluoro)phenylamino-cyclohexan-1-one (3e)}

${ }^{1} \mathrm{H}$ NMR $\left(500 \mathrm{MHz}, \mathrm{CDCl}_{3}\right) \delta$ 7.03-6.99 $(\mathrm{m}, 1 \mathrm{H})$, 6.95-6.93 (m, 1H), 6.81-6.78 (m, 1H), 6.76-6.67 (m, 1H), 3.91-3.87 (m, 1H), 2.88-2.84 (m, 1H), 2.39-2.33 (m, 3H), 2.26-2.22 (m, 1H), 2.09-2.06 (m, 1H), 1.76-1.70 (m, 2H).

\section{3-(4-Fluoro)phenylamino-cyclohexan-1-one (3f)}

${ }^{1} \mathrm{H}$ NMR $\left(500 \mathrm{MHz}, \mathrm{CDCl}_{3}\right) \delta 6.88(\mathrm{~d}, 2 \mathrm{H}, J 8.9 \mathrm{~Hz})$, $6.54(\mathrm{dd}, 2 \mathrm{H}, J$ 8.9, $4.4 \mathrm{~Hz}), 3.73-3.68(\mathrm{~m}, 1 \mathrm{H}), 3.54(\mathrm{sl}$, $1 \mathrm{H}), 2.83-2.78(\mathrm{~m}, 1 \mathrm{H}), 2.37-2.25(\mathrm{~m}, 3 \mathrm{H}), 2.19-2.14(\mathrm{~m}$, $1 \mathrm{H}), 2.07-2.02(\mathrm{~m}, 1 \mathrm{H}), 1.76-1.66(\mathrm{~m}, 2 \mathrm{H})$. 
3-(2-Methoxy)phenylamino-cyclohexan-1-one (3g)

${ }^{1} \mathrm{H}$ NMR $\left(500 \mathrm{MHz}, \mathrm{CDCl}_{3}\right) \delta 6.88$ (ddd, $1 \mathrm{H}, J$ 7.7 , 7.7, $1.5 \mathrm{~Hz}), 6.80$ (dd, $1 \mathrm{H}, J 8.0,1.5 \mathrm{~Hz}), 6.70$ (ddd, $1 \mathrm{H}, J 7.7$, 7.7, $1.5 \mathrm{~Hz}), 6.62(\mathrm{dd}, 1 \mathrm{H}, J 8.0,1.5 \mathrm{~Hz}), 3.85(\mathrm{~s}, 3 \mathrm{H})$, 3.79-3.75 (m, 1H), 2.87-2.83 (m, 1H), 2.38-2.30 (m, 3H), 2.24-2.19 (m, 1H), 2.10-2.04 (m, 1H), 1.77-1.70 (m, 2H).

3-(4-Methoxy)phenylamino-cyclohexan-1-one (3h)

${ }^{1} \mathrm{H}$ NMR $\left(500 \mathrm{MHz}, \mathrm{CDCl}_{3}\right) \delta 6.78(\mathrm{~d}, 2 \mathrm{H}, J 8.9 \mathrm{~Hz})$, $6.58(\mathrm{~d}, 2 \mathrm{H}, J 8.9 \mathrm{~Hz}), 3.74(\mathrm{~s}, 3 \mathrm{H}), 3.71-3.66(\mathrm{~m}, 1 \mathrm{H}), 2.80$ (m, $1 \mathrm{H}), 2.39-2.33(\mathrm{~m}, 3 \mathrm{H}), 2.18-2.16(\mathrm{~m}, 1 \mathrm{H}), 2.03-2.02$ $(\mathrm{m}, 1 \mathrm{H}), 1.76-1.70(\mathrm{~m}, 2 \mathrm{H})$.

3-(4-Chloro)phenylamino-cyclohexan-1-one (3i)

${ }^{1} \mathrm{H}$ NMR $\left(500 \mathrm{MHz}, \mathrm{CDCl}_{3}\right) \delta 7.13(\mathrm{~d}, 2 \mathrm{H}, J 8.9 \mathrm{~Hz})$, $6.52(\mathrm{~d}, 2 \mathrm{H}, J 8.9 \mathrm{~Hz}), 3.75(\mathrm{~m}, 1 \mathrm{H}), 2.84-2.80(\mathrm{~m}, 1 \mathrm{H})$, 2.38-2.31 (m, 3H), 2.20-2.17 (m, 1H), 2.05-2.02 (m, 1H), $1.79-1.70(\mathrm{~m}, 2 \mathrm{H})$.

\section{3-(4-Bromo)phenylamino-cyclohexan-1-one (3j)}

${ }^{1} \mathrm{H}$ NMR $\left(500 \mathrm{MHz}, \mathrm{CDCl}_{3}\right) \delta 7.25(\mathrm{~d}, 2 \mathrm{H}, J 9.0 \mathrm{~Hz})$, 6.47 (d, 2H, J 8.9 Hz), 3.76-3.69 (m, 1H), 2.82-2.78 (m, $1 \mathrm{H}), 2.37-2.29(\mathrm{~m}, 3 \mathrm{H}), 2.18-2.14(\mathrm{~m}, 1 \mathrm{H}), 2.05-2.03(\mathrm{~m}$, $1 \mathrm{H}), 1.77-1.70(\mathrm{~m}, 2 \mathrm{H})$.

\section{3-(4-Methyl)phenylamino-cyclohexan-1-one (3k)}

${ }^{1} \mathrm{H}$ NMR $\left(500 \mathrm{MHz}, \mathrm{CDCl}_{3}\right) \delta 7.00(\mathrm{~d}, 2 \mathrm{H}, J 8.5 \mathrm{~Hz})$, $6.54(\mathrm{~d}, 2 \mathrm{H}, J 8.5 \mathrm{~Hz}), 3.75(\mathrm{~m}, 1 \mathrm{H}), 2.82(\mathrm{~m}, 1 \mathrm{H}), 2.37-$ $2.31(\mathrm{~m}, 3 \mathrm{H}), 2.25$ (s, 3H), 2.20-2.17 (m, 1H), 2.05-2.02 $(\mathrm{m}, 1 \mathrm{H}), 1.76-1.69(\mathrm{~m}, 2 \mathrm{H})$.

3-Imidazole-cyclohexan-1-one (3I)

${ }^{1} \mathrm{H}$ NMR $\left(500 \mathrm{MHz}, \mathrm{CDCl}_{3}\right) \delta 7.49(\mathrm{~s}, 1 \mathrm{H}), 7.00(\mathrm{t}, 1 \mathrm{H}$, $J 1.18 \mathrm{~Hz}), 6.93(\mathrm{t}, 1 \mathrm{H}, J 1.39 \mathrm{~Hz}), 4.74(\mathrm{~m}, 1 \mathrm{H}), 2.78(\mathrm{~m}$, $1 \mathrm{H}), 2.44-2.33(\mathrm{~m}, 3 \mathrm{H}), 2.29-2.26(\mathrm{~m}, 1 \mathrm{H}), 2.05-2.01(\mathrm{~m}$, $1 \mathrm{H}), 1.74-1.64(\mathrm{~m}, 2 \mathrm{H})$.

\section{3-(1-Naphthylamino)-cyclohexan-1-one (3m)}

${ }^{1} \mathrm{H}$ NMR $\left(500 \mathrm{MHz}, \mathrm{CDCl}_{3}\right) \delta$ 7.85-7.80 (m, 2H), 7.49-7.46 (m, 2H), 7.37-7.30 (m, 2H), 6.80 (dd, 1H, J 6.9, $1.5 \mathrm{~Hz}), 4.21(\mathrm{sl}, 1 \mathrm{H}), 4.01(\mathrm{~m}, \mathrm{H}), 2.98(\mathrm{~m}, 1 \mathrm{H}), 2.38-2.33$ $(\mathrm{m}, 3 \mathrm{H}), 2.14-2.09(\mathrm{~m}, 1 \mathrm{H}), 2.05-2.03(\mathrm{~m}, 1 \mathrm{H}), 1.88-1.83$ (m, 2H).

General procedure for ion-fishing of supramolecular adduct using ESI(+)-MS

A mixture of aniline $(0.24 \mathrm{~mL}, 2.6 \mathrm{mmol})$ and cycloexen-2-one $(0.25 \mathrm{~mL}, 1.0$ equiv, $2.6 \mathrm{mmol})$ was stirred magnetically at room temperature in the presence of ionic liquid ( 0.3 equiv.). After $15 \mathrm{~min}$, an aliquot portion
$(10 \mu \mathrm{L})$ of the reaction mixture was taken out by micro pipette and dissolved in acetonitrile $(1 \mathrm{~mL})$ and when necessary, formic acid (1\%). From the resultant solution an aliquot amount $(50 \mu \mathrm{L})$ was subjected to ESI(+)-MS. Sampling was performed every $15 \mathrm{~min}$ for $120 \mathrm{~min}$ of reaction.

The ion-fishing study was performed on a highresolution mass spectrometer (Impact II, Bruker Daltonics Corporation, Germany), equipped with an electrospray ionization source. The capillary voltage was operated in positive ionization mode, set at $4000 \mathrm{~V}$ and with an end plate potential of $-500 \mathrm{~V}$. The dry gas parameters were set to $10 \mu \mathrm{L} \mathrm{min}^{-1}$ at $180{ }^{\circ} \mathrm{C}$ with a nebulization gas pressure of 0.4 bar. Data were collected from $\mathrm{m} / \mathrm{z}$ 50-500 with an acquisition rate of 5 spectra per $\mathrm{s}$, and the ions of interest were selected to MS/MS fragmentation.

\section{Computational methods}

Theoretical calculations were performed with the Gaussian 09 program package, revision B.01. ${ }^{29}$ The PyMOL program ${ }^{30}$ was used to visualize structures and surfaces. The structures of supramolecular complexes were optimized using the density functional method M06-2X ${ }^{31}$ coupled with the $6-31++\mathrm{G}(\mathrm{d}, \mathrm{p})$ basis set function. ${ }^{32}$ Frequency calculations were performed to characterize the structure as a minimum or as a transition state (TS) and to obtain the zero-point energy (ZPE) ${ }^{33}$ and thermal correction to Gibbs free energy. Corrections due to basis set superposition error $(\mathrm{BSSE})^{34}$ were also calculated at the same level of theory for the complexes. In order to confirm that the transitional state connects the desired reaction, intrinsic reaction coordinate (IRC) calculations were performed at the same level of theory of the optimizations.

\section{Results and Discussion}

Synthesis and catalytic potential evaluation of the DBU-based ILs

The route to synthesize the DBU-based ILs and their structures are presented in Scheme 1. The synthetic procedures and the characterization are discussed in details in the Experimental section. [HDBU][Ac], [HDBU][TFA] and [HDBU][OTs] were obtained in a single step with the addition of the carboxylic acid directly to the DBU base, according to procedures previously described in the literature. ${ }^{24,28}$ The ILs [HDBU] $\left[\mathrm{HSO}_{4}\right]$, [HDBU] $\left[\mathrm{BF}_{4}\right]$, $[\mathrm{BDBU}]\left[\mathrm{HSO}_{4}\right]$ and $[\mathrm{BDBU}]\left[\mathrm{BF}_{4}\right]$ were obtained according to the methodology used to obtain imidazole-based ILs. $[\mathrm{HDBU}]\left[\mathrm{HSO}_{4}\right]^{16}$ was obtained in a single step from the 
reaction of DBU with $\mathrm{H}_{2} \mathrm{SO}_{4}$ in acetonitrile. However, the $[\mathrm{BDBU}]\left[\mathrm{HSO}_{4}\right]$ and $[\mathrm{BDBU}]\left[\mathrm{BF}_{4}\right]$ were obtained in two steps, from DBU reaction with butyl bromide leading to the formation of [BDBU] $\mathrm{Br}]$, followed by anion exchange in the presence of $\mathrm{H}_{2} \mathrm{SO}_{4}{ }^{20}$ and $\mathrm{NaBF}_{4},{ }^{19}$ respectively. [HDBU $]\left[\mathrm{BF}_{4}\right]$ was also obtained in two steps, from DBU reaction with hydrobromic acid leading to the formation of $[\mathrm{HDBU}][\mathrm{Br}]$, followed by anion exchange in the presence of $\mathrm{NaBF}_{4} \cdot{ }^{16,19}$ All ILs were obtained in satisfactory yields (90-96\%) and were characterized by NMR analysis (see, Supplementary Information (SI) section).

Firstly, the catalytic potential of the ILs was evaluated for the aza-Michael addition of aniline to 2-cyclohexen1-one (Table 1). For comparison, some imidazolium ILs were also used in the model reaction. A summary of the results obtained is provided in Table 1 .

Table 1. Aza-Michael addition of aromatic amines to 2-cycloexen-1-one catalyzed by ILs ${ }^{\mathrm{a}}$

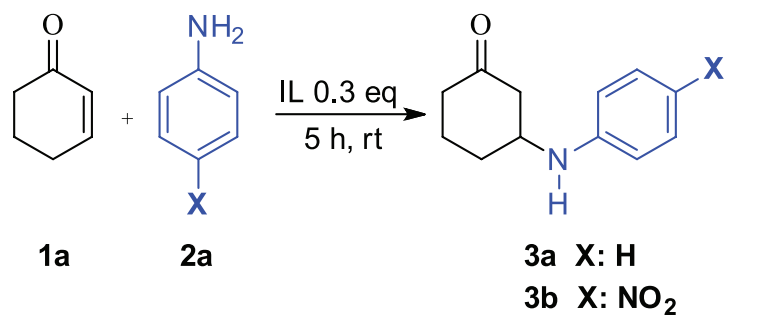

\begin{tabular}{|c|c|c|c|c|}
\hline \multirow[b]{2}{*}{ IL } & \multicolumn{2}{|r|}{$\mathrm{X}: \mathrm{H}$} & \multicolumn{2}{|c|}{$\mathrm{X}: \mathrm{NO}_{2}$} \\
\hline & entry & $\begin{array}{c}\text { Conversion }^{\mathrm{b}} / \\
\%\end{array}$ & entry & $\begin{array}{c}\text { Conversion }^{\mathrm{b}} / \\
\%\end{array}$ \\
\hline$[\mathrm{HDBU}][\mathrm{Ac}]$ & 1 & $85(58)^{c}$ & 12 & 32 \\
\hline [HDBU][TFA] & 2 & 87 & 13 & 84 \\
\hline [HDBU][OTs] & 3 & 42 & 14 & 89 \\
\hline$[\mathrm{HDBU}]\left[\mathrm{BF}_{4}\right]$ & 4 & 83 & 15 & 75 \\
\hline$[\mathrm{HDBU}]\left[\mathrm{HSO}_{4}\right]$ & 5 & $82(80)^{c}$ & 16 & $91(89)^{c}$ \\
\hline$[\mathrm{BDBU}]\left[\mathrm{HSO}_{4}\right]$ & 6 & $80^{\mathrm{d}}$ & 17 & $--^{\mathrm{d}, \mathrm{e}}$ \\
\hline$[\mathrm{BDBU}]\left[\mathrm{BF}_{4}\right]$ & 7 & 39 & 18 & $--^{e}$ \\
\hline$[\mathrm{Hmin}]\left[\mathrm{HSO}_{4}\right]$ & 8 & 35 & 19 & 86 \\
\hline$[\mathrm{Bmin}]\left[\mathrm{HSO}_{4}\right]$ & 9 & 79 & 20 & 90 \\
\hline$[\mathrm{Bmin}][\mathrm{OH}]$ & 10 & $68^{f}$ & 21 & - \\
\hline None & 11 & $-^{\mathrm{e}}$ & 22 & $-^{\mathrm{e}}$ \\
\hline
\end{tabular}

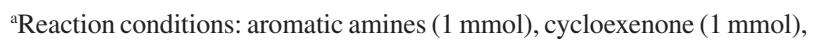
IL $0.3 \mathrm{~mol} \%$; 'betermined by ${ }^{1} \mathrm{H}$ NMR; ' reaction for $3 \mathrm{~h}$; ${ }^{\mathrm{d}}$ reaction at $60{ }^{\circ} \mathrm{C}$; ${ }^{e}$ no reaction; ${ }^{\mathrm{f}}$ reference 17 , reaction for $9 \mathrm{~h}$. IL: ionic liquid; DBU: 1,8-diazabicyclo[5.4.0]undec-7-ene; TFA: trifluoroacetate.

Ionic liquids [HDBU][Ac], [HDBU][TFA], $[\mathrm{HDBU}]\left[\mathrm{BF}_{4}\right]$ and $[\mathrm{HDBU}]\left[\mathrm{HSO}_{4}\right]$ were found to be very effective and afforded the desired aza-Michael adduct in high conversion rates at room temperature and solvent free conditions (Table 1, entries 1, 2, 4 and 5, respectively).
Since $[\mathrm{BDBU}]\left[\mathrm{HSO}_{4}\right]$ is a very viscous ILs the reaction was performed at $60^{\circ} \mathrm{C}$ (Table 1 , entry 6).

The low catalytic efficiency of $[\mathrm{BDBU}]\left[\mathrm{BF}_{4}\right]$ suggests that the protic cation plays a relevant role in the catalysis of the reaction (Table 1, entry 7). However, the high catalytic efficiency of $[\mathrm{BDBU}]\left[\mathrm{HSO}_{4}\right]$ led us to believe that the protic anion also could be responsible for catalysis (Table 1, entry 6).

The efficiency of the ILs on the addition of $p$-nitroaniline, a poor nucleophile, to 2-cyclohexen-1-one has also been assessed. [HDBU][TFA], [HDBU][OTs], [HDBU] $\left[\mathrm{BF}_{4}\right]$ and $[\mathrm{HDBU}]\left[\mathrm{HSO}_{4}\right]$ showed to be very effective at room temperature and solvent free conditions (Table 1, entries 13-16). It is important to note that the reaction with [HDBU] $\left[\mathrm{HSO}_{4}\right]$ occurred in a shorter time $(3 \mathrm{~h})$ than for the other evaluated ILs $(5 \mathrm{~h})$ without significant decrease in yield. Among imidazolium ILs used, only $[\mathrm{Bmin}]\left[\mathrm{HSO}_{4}\right]$ promoted the reaction with an efficiency comparable to $[\mathrm{HDBU}]\left[\mathrm{HSO}_{4}\right]$.

With the efficient catalytic system in hand, we examine the utility and generality of a wide range of aromatic amines for the [HDBU] $\left[\mathrm{HSO}_{4}\right]$-aza-Michael reactions using cycloexen-2-one as substrate. All results summarized in Table 2 shown good to excellent conversion rates (entries 1-11), including aromatic amines with high electron-withdrawing group at benzene ring (entries, 1-3). Four novel adducts $(\mathbf{3 c}, \mathbf{3 d}, \mathbf{3 g}$ and $\mathbf{3 m})$ were obtained (Table 2, entries, 1, 2, 5 and 11) showing the great versatility of the ionic liquid [HDBU] $\left[\mathrm{HSO}_{4}\right]$. In addition, $[\mathrm{HDBU}]\left[\mathrm{HSO}_{4}\right]$ presented a lower reaction time when compared to other DBU derivatives reported in the literature, ${ }^{1,24,25}$ showing to be an excellent catalyst for the

Table 2. Aza-Michael addition of aromatic amines to 2-cycloexen-1-one catalyzed by $[\mathrm{HDBU}]\left[\mathrm{HSO}_{4}\right]^{\mathrm{a}}$

\begin{tabular}{lccc}
\hline entry & Amine & Product & Conversion ${ }^{\mathrm{b}} \%$ \\
\hline 1 & $o-\mathrm{NO}_{2} \mathrm{C}_{6} \mathrm{H}_{4} \mathrm{NH}_{2}$ & $\mathbf{3 c}$ & 87 \\
2 & $m-\mathrm{NO}_{2} \mathrm{C}_{6} \mathrm{H}_{4} \mathrm{NH}_{2}$ & $\mathbf{3 d}$ & 87 \\
3 & $o-\mathrm{F}_{6} \mathrm{C}_{6} \mathrm{H}_{4} \mathrm{NH}_{2}$ & $\mathbf{3 e}$ & 93 \\
4 & $p-\mathrm{F}_{6} \mathrm{C}_{6} \mathrm{H}_{4} \mathrm{NH}_{2}$ & $\mathbf{3 f}$ & 91 \\
5 & $o-\mathrm{OCH}_{3}-\mathrm{C}_{6} \mathrm{H}_{4} \mathrm{NH}_{2}$ & $\mathbf{3 g}$ & 83 \\
6 & $p-\mathrm{OCH}_{3}-\mathrm{C}_{6} \mathrm{H}_{4} \mathrm{NH}_{2}$ & $\mathbf{3 h}$ & 71 \\
7 & $p-\mathrm{Cl}_{-} \mathrm{C}_{6} \mathrm{H}_{4} \mathrm{NH}_{2}$ & $\mathbf{3 i}$ & 85 \\
8 & $p-\mathrm{Br}_{6} \mathrm{C}_{6} \mathrm{H}_{4} \mathrm{NH}_{2}$ & $\mathbf{3 j}$ & 85 \\
9 & $p-\mathrm{CH}_{3}-\mathrm{C}_{6} \mathrm{H}_{4} \mathrm{NH}_{2}$ & $\mathbf{3 k}$ & 78 \\
10 & imidazole & $\mathbf{3 l}$ & 74 \\
11 & $1-$ naphthylamine & $\mathbf{3 m}$ & 65 \\
\hline
\end{tabular}

aReaction conditions: aromatic amines $(1 \mathrm{mmol})$, Michael acceptors

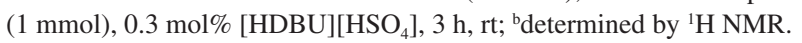


aza-Michael reaction of aromatic amines, which present low reactivity with other ILs. As per the literature survey, till date, there have been no reports on the use of [HDBU] $\left[\mathrm{HSO}_{4}\right]$ as catalyst for carrying out aza-Michael addition between various deactivated arylamines with Michael acceptor.

\section{Supramolecular assembly by ESI-MS study}

Electrospray ionization mass spectrometry (ESI-MS) study was performed to investigate effective catalyst role in the aza-Michael addition for the reaction between 2-cyclohexen-1-one (1a) and aniline (2a) using different DBU-based ionic liquids. The catalytic role of DBU-based IL with the substrates is envisaged through the formation of the non-covalent complex (NCC) by electrophile nucleophile dual activation (Scheme 2) similar to related in literature for $[\mathrm{Bmin}]\left[\mathrm{MeSO}_{4}\right]{ }^{35}$

The total ion chromatogram (TIC) from the [HDBU] $\left[\mathrm{HSO}_{4}\right]$ catalyzed reaction (Figures $\mathrm{S} 19$ and S20, SI section) revealed the presence of ions at $\mathrm{m} / \mathrm{z} 439.2708\left(\mathrm{~m}_{1}\right), 364.2243$ $\left(\mathrm{m}_{2}\right), 361.2246\left(\mathrm{~m}_{3}\right), 343.2142\left(\mathrm{~m}_{4}\right), 286.1781\left(\mathrm{~m}_{5}\right)$, $268.1677\left(\mathrm{~m}_{6}\right), 190.1216\left(\mathrm{~m}_{7}\right), 172.1111\left(\mathrm{~m}_{8}\right), 153.1385$ $\left(\mathrm{m}_{9}\right)$ and $94.0648\left(\mathrm{~m}_{10}\right)$, which are corresponding to [NCC], [imine $\left.+2 \times \mathbf{1 a}+\mathrm{H}^{+}\right]$, [imine $\left.+\mathbf{3 a}+\mathrm{H}^{+}\right],\left[2 \times\right.$ imine $\left.+\mathrm{H}^{+}\right]$, $\left[\mathbf{1} \mathbf{a}+\mathbf{3 a}+\mathrm{H}^{+}\right]$, [imine $\left.+\mathbf{1 a}+\mathrm{H}^{+}\right],\left[\mathbf{3} \mathbf{a}+\mathrm{H}^{+}\right]$, [imine $\left.+\mathrm{H}^{+}\right]$, $\left[\mathrm{DBU}+\mathrm{H}^{+}\right]$and $\left[\mathbf{2} \mathbf{a}+\mathrm{H}^{+}\right]$, respectively.

The support for determination of non-covalent complex was obtained from the mass (MS/MS) studies of 439.2684 $\left(\mathrm{m}_{1}\right)$ ion observed in the TIC. ESI(+)-MS/MS revealed the presence of ions at $m / z 346.2118,268.1660,250.1556$ and 172.1098 that are assigned in Figure 1.

The TICs for the reactions between 2-cyclohexen1-one and aniline with ILs [HDBU][Ac], [HDBU][TFA],
[HDBU][OTs] and [HDBU] $\left[\mathrm{BF}_{4}\right]$ also show the ions of the supramolecular complexes, suggesting that these ILs catalyze the aza-Michael addition in the same way that [HDBU] $\left[\mathrm{HSO}_{4}\right]$.

On the other hand, the TIC from the reaction between 2-cyclohexen-1-one and aniline with [BDBU] $\left[\mathrm{HSO}_{4}\right]$ (Figures S30, S31 and S32, SI section), revealed only the presence of ions at $\mathrm{m} / \mathrm{z} 268.1693\left(\mathrm{~d}_{2}\right), 209.2012\left(\mathrm{~d}_{3}\right)$, $190.1224\left(d_{4}\right), 172.1118\left(d_{5}\right), 153.1384\left(d_{6}\right)$ and $94.0650\left(d_{7}\right)$ corresponding to [imine $\left.+\mathbf{1 a}+\mathrm{H}^{+}\right],[\mathrm{BDBU}]^{+},\left[\mathbf{3 a}+\mathrm{H}^{+}\right]$, [imine $\left.+\mathrm{H}^{+}\right],\left[\mathrm{DBU}+\mathrm{H}^{+}\right]$, and $\left[\mathbf{2} \mathbf{a}+\mathrm{H}^{+}\right]$, respectively. An equivalent mass pattern for the non-covalent complex between the 1a, 2a and [BDBU] $\left[\mathrm{HSO}_{4}\right]$ was not detected $(\mathrm{m} / \mathrm{z}$ 495.2767).

These results are in accordance with the catalytic model proposed (Scheme 2), pointing out that the protic cation plays a relevant role in the catalysis of the reaction. In this model, there are the formation of a non-covalent complex (Scheme 2) in which the acidic hydrogen of cation DBU forms a hydrogen bond with the carbonyl oxygen of Michael acceptor (1a) (electrophilic activation), while the oxygen atom of one of the $\mathrm{S}=\mathrm{O}$ group in $\mathrm{HSO}_{4}{ }^{-}$forms a hydrogen bond with the $\mathrm{N}-\mathrm{H}$ hydrogen of aromatic amine and drives the $\beta$-carbon attack (nucleophilic activation). Nucleophilic attack followed by transfer of proton from the $\mathrm{NH}_{2}$ group of $\mathbf{2 a}$ through the hydrogen bridge in the hydrogen bonded cluster to the carbonyl oxygen of $1 \mathrm{a}$ forms the enol of the aza-Michael adduct 3a and brings the IL back to the catalytic cycle. In the case of [BDBU] $\left[\mathrm{HSO}_{4}\right]$, we suppose that the reaction occurs by another path, where the acidic hydrogen of the anion may be activating the carbonyl of 2a.

The decrease in the conversion of $\mathbf{3 a}$ using $[\mathrm{BDBU}]\left[\mathrm{BF}_{4}\right]$ (Table 1, entry 8 ) that has an aprotic cation (moiety that
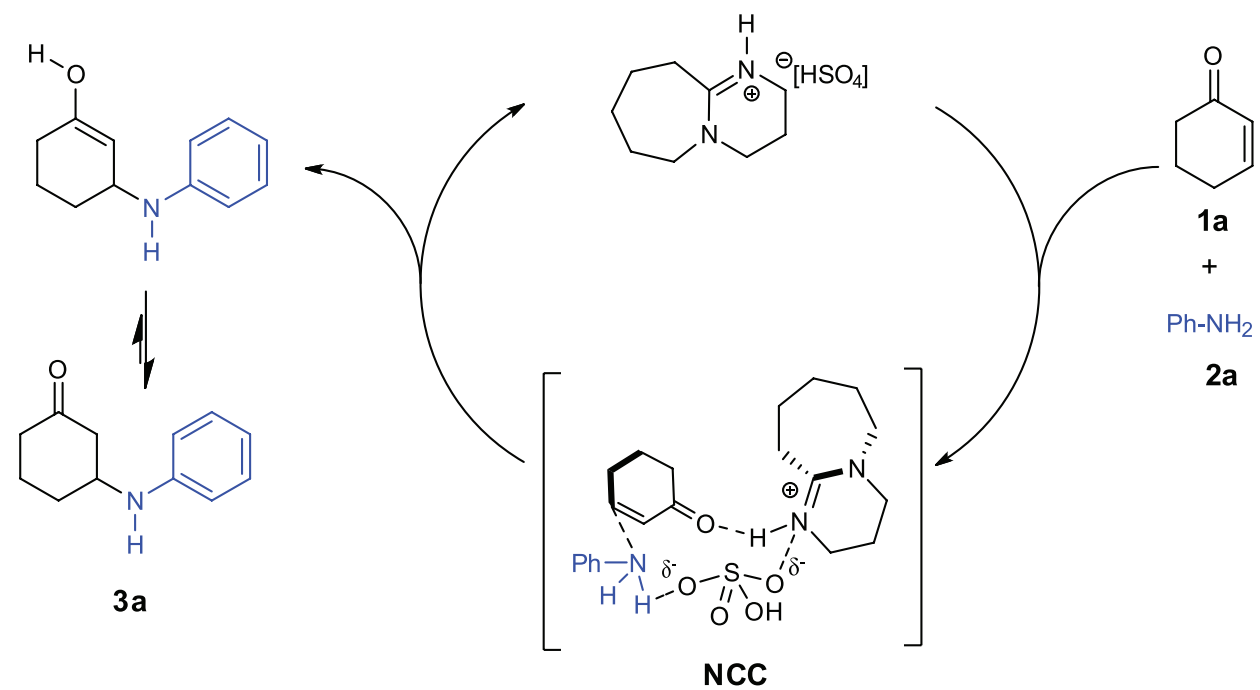

Scheme 2. Catalytic role of DBU-based IL in the aza-Michael reaction. 


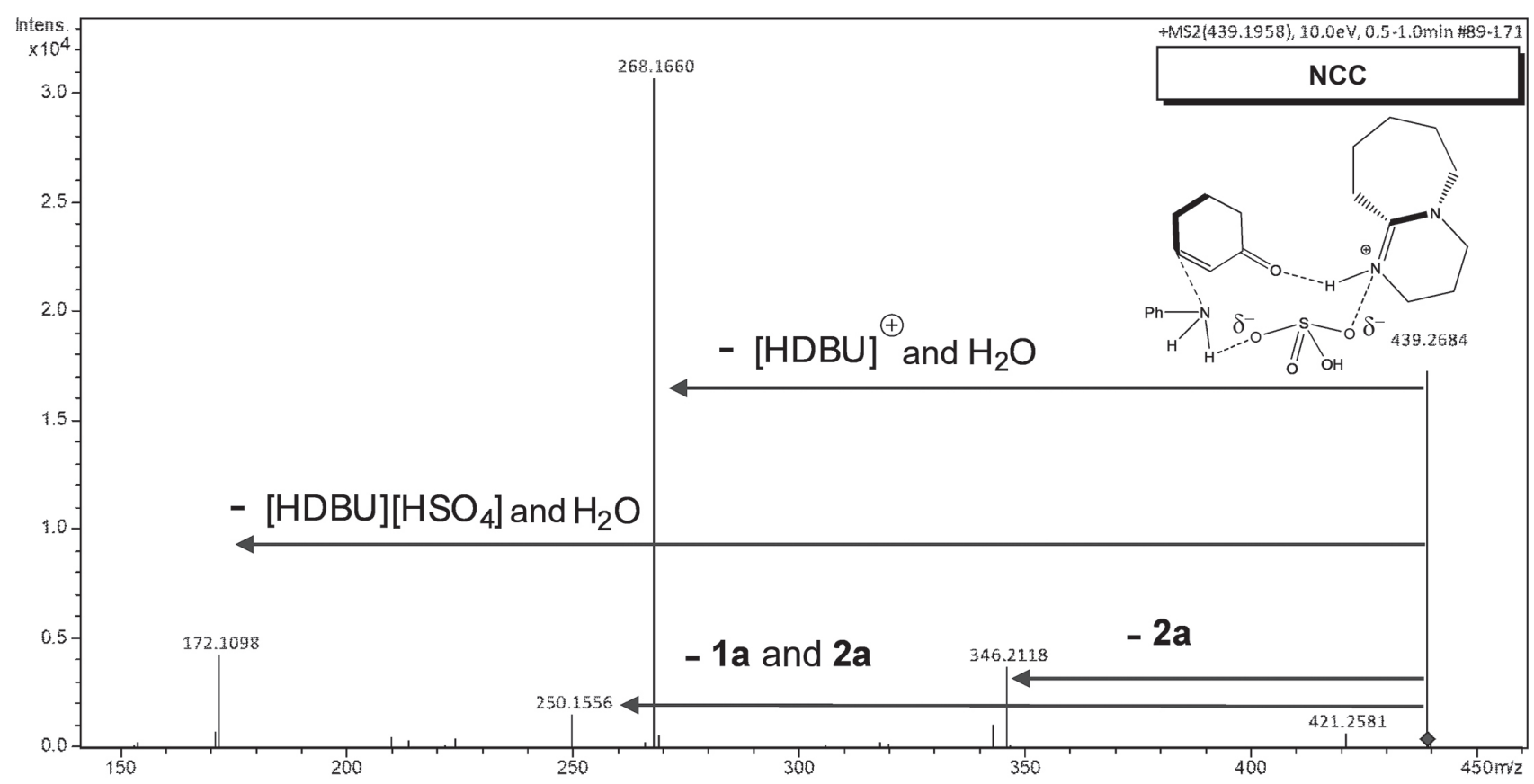

Figure 1. ESI(+)-MS/MS of NCC $\left(\mathrm{m}_{1}\right)$ withdrawn after $2 \mathrm{~h}$ for the reaction of 2 cicloexen-1-one and aniline catalyzed by [HDBU][HSO $\left.{ }_{4}\right]$.

supports electrophilic activation) and also do not have acidic hydrogen in the anion corroborate the catalyst role proposed (Scheme 2).

ESI-MS analysis was also performed for the reaction between 2-cyclohexen-1-one (1a) and cyclohexylamine (2b) with $[\mathrm{HDBU}]\left[\mathrm{HSO}_{4}\right]$ to evaluate if aza-Michael addition of aliphatic amines occurs by the same mechanism proposed for the aromatic amines. For this reaction, an equivalent mass pattern for the non-covalent complex $(\mathrm{m} / \mathrm{z}$ 445.2610) between the reactants and IL was not detected in the TIC (Figure S33, SI section). Aliphatic amines are not good donor of $\mathrm{N}-\mathrm{H}$ hydrogen to form the hydrogen bond with the IL anion, which is determinant for the formation of the non-covalent complex. This result confirms that the nucleophilic activation by the IL anion had crucial role in aza-Michael addition of aromatic amines.

\section{Theoretical investigation of mechanism reaction}

The purpose of including the theoretical study here was to corroborate the catalytic role proposed from experimental analysis. For the reaction with [HDBU] $\left[\mathrm{HSO}_{4}\right]$ were optimized: a transition state for each reaction step (TS1 and TS2); an initial complex involving reagents and the IL; a complex involving the intermediate and the IL; and a complex involving the Michael products and the IL. The results obtained from the mass spectrometry experiments were used for the rational construction of the complex involving the reagents and also for the TS1 transition state.
The optimized structures and the energy diagram for the aza-Michael addition are shown in Figure 2. The dotted lines indicate for transitional states a normal vibration coordinate. The transition state for the first step of the reaction (TS1), involving the addition of aniline to $\beta$-carbon of 2-cyclohexen-1-one was characterized by IRC calculations. In TS1 is observed the approximation of the nitrogen of $\mathbf{2 a}$ to the $\beta$ carbon of $\mathbf{1 a}$, one of the hydrogen of the amino group of $\mathbf{2 a}$ toward $\mathrm{HSO}_{4}{ }^{-}$anion and two interactions toward carbonyl oxygen of $\mathbf{1 a}$, one of the acidic hydrogen of the cation and other of the anion hydrogen. This shows that both the cation and the counter ion play a key role in the catalysis of the reaction. These results are in agreement with the data obtained experimentally. When the IL is no protic, it is not possible to form the non-covalent complex and then this catalytic efficiency decreases, as verified for [BDBU] $\left[\mathrm{BF}_{4}\right]$ (Table 1, entry 8). In TS2, it is observed the transfer of a hydrogen from sulfuric acid to the $\alpha$ carbon of the enol and the removal of the hydrogen from the carbonyl protonated by the DBU, restoring the ionic liquid, according catalytic cycle proposed (Scheme 1).

Calculated Gibbs energy shows that the products are more stable than reagents and intermediate (enol). The activation Gibbs energy calculated for TS1 is $20.2 \mathrm{kcal} \mathrm{mol}^{-1}$, and for TS2 is $6.8 \mathrm{kcal} \mathrm{mol}^{-1}$. Thus, the ionic liquid acts directly on the determining step of the reaction rate.

The results obtained for the [HDBU][Ac] and [HDBU] [TFA] are similar and data are compiled in Table S1, 


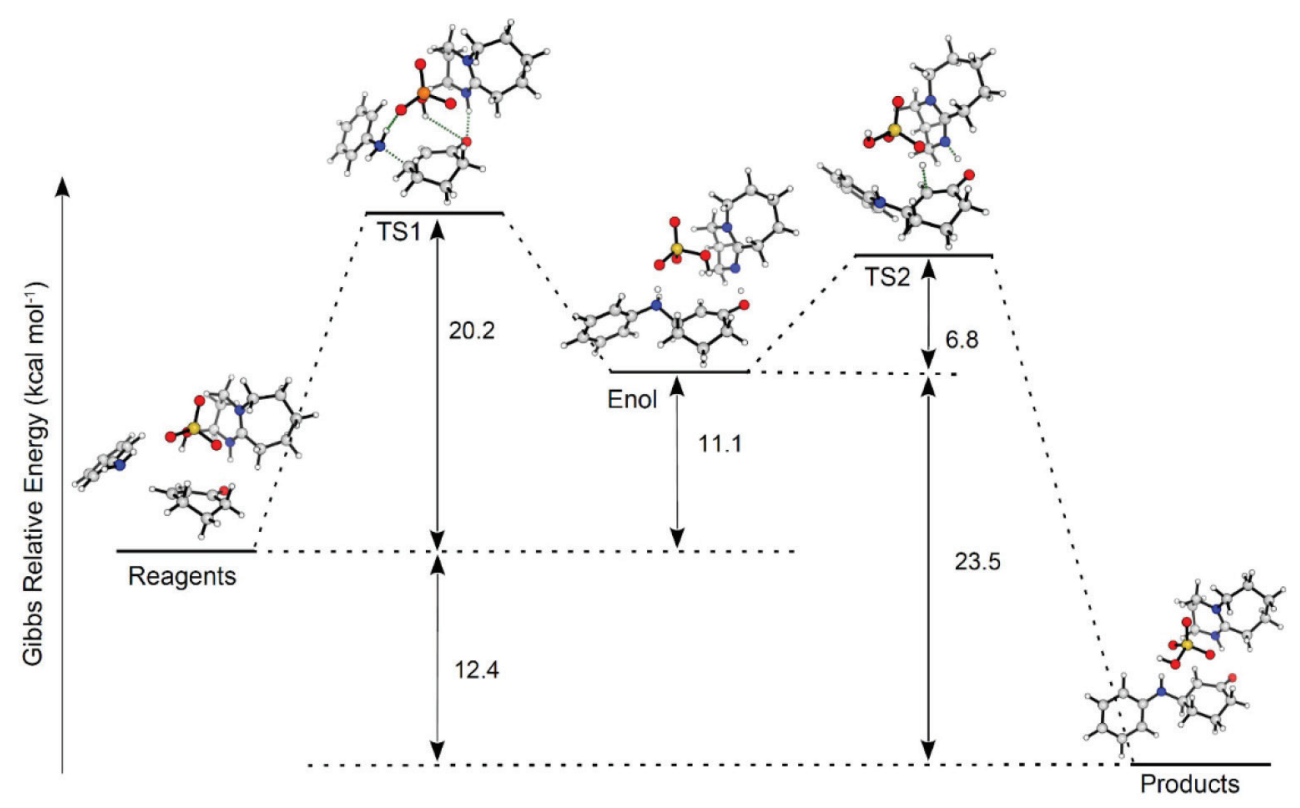

Figure 2. Gibbs relative energies of reaction between 2-cycloexen-1-one and aniline with $[\mathrm{HDBU}]\left[\mathrm{HSO}_{4}\right]$ at the M06-2X/6-31++G(d,p).

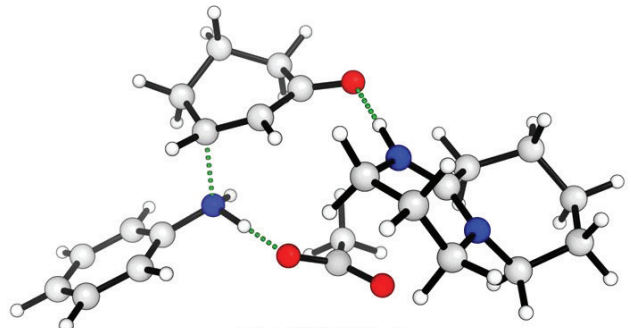

TS1-[HDBU][Ac]

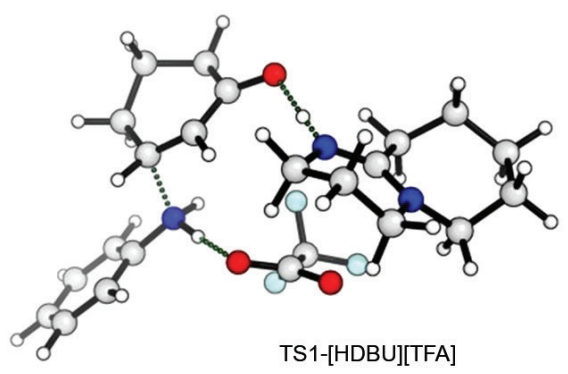

TS1-[HDBU][TFA]

Figure 3. Complex optimized for TS1 in the reactions between 2-cyclohexen-1-one and aniline with the ILs studied in M06-2X/6-31++G (d,p).

Figures S36 and S37 (SI section). The optimized geometries of TS1 for reaction catalyzed by [HDBU][Ac] and [HDBU] [TFA] are illustrated in Figure 3 and show that there are three important interactions when the anion does not have acidic hydrogen: the approximation of the nitrogen of $\mathbf{2 a}$ to the $\beta$ carbon of $\mathbf{1 a}$, one of the hydrogen of the amino group of 2a toward anion and the acidic hydrogen of the cation toward carbonyl oxygen of $\mathbf{1 a}$.

\section{Conclusions}

The detailed mechanism of aza-Michael adducts formation from 2-cycloexen-1-one with aromatic amines promoted by DBU-based ILs has been examined using ESI-MS experiments and DFT calculations. The cations and anions of ionic liquids are found to synergistically promote the addition reaction by nucleophilic activation and proton transfer and simultaneously stabilizing transition states by hydrogen bonding interaction. The non-covalent complex formed between reagents and ILs have been identified and characterized by ESI-MS. The mechanistic model proposed can be used as basis of rational design and selection of organocatalysts.

\section{Supplementary Information}

Supplementary information is available free of charge at http://jbcs.sbq.org.br as PDF file.

\section{Acknowledgments}

The authors thank Fundação Araucária (002/17) and CNPq (404455/2016-6) for their financial support, CAPES for the fellowships of A. M. F. R. and J. R. B. S. Research developed with the help of CENAPAD-SP (National Project for High Performance Processing in São Paulo), UNICAMP/FINEP-MCT project.

\section{Author Contributions}

GiseleF. Gauze was responsible for the conceptualization, formal analysis, funding acquisition, project administration, 
supervision, writing original draft, review and editing; Augusto A. Cândido for the investigation, methodology, validation, data curation and writing original draft; Thiago C. Rozada for the investigation, methodology, data curation, visualization and software of theoretical calculations; Andrew M. F. Rozada for investigation, methodology, formal analysis and writing original draft; João R. B. Souza for the investigation, methodology, data curation, visualization and ESI-MS experiments; Eduardo J. Pilau for the supervision, writing orignal draft and software of ESI-MS experiments; Fernanda A. Rosa for the conceptualization, supervision, writing review and editing; Ernani A. Basso for the project administration, supervision, writing review and editing.

\section{References}

1. Roy, D.; Panda, G.; Synthesis 2019, 51, 4434.

2. Szanti-Pinter, E.; Skoda-Földes, R.; Curr. Green Chem. 2018, 5,4 .

3. Vinogradov, M. G.; Turova, O. V.; Zlotin, S. G.; Org. Biomol. Chem. 2019, 17, 3670.

4. Yamazaki, D. A. S.; Cândido, A. A.; Bagatin, M. C.; Machinski, M.; Mossini, S. A. G.; Pontes, R. M.; Rosa, F. A.; Basso, E. A.; Gauze, G. F.; J. Braz. Chem. Soc. 2016, 27, 1616.

5. Azizi, N.; Saidi, M. R.; Tetrahedron 2004, 60, 383.

6. Xu, L. W.; Li, L.; Xia, C. G.; Helv. Chim. Acta 2004, 87, 1522.

7. Srivastava, N.; Banik, B. K.; J. Org. Chem. 2003, 68, 2109.

8. Matsubara, S.; Yoshioka, M.; Utimoto, K.; Chem. Lett. 1994, 23,827 .

9. Jener, G.; Tetrahedron Lett. 1995, 36, 233.

10. Duan, Z.; Xuan, X.; Li, T.; Yang, C.; Wu, Y.; Tetrahedron Lett. 2006, 47, 5433.

11. Scettri, A.; Massa, A.; Palombi, L.; Villano, R.; Acocella, M. R.; Tetrahedron: Asymmetry 2008, 19, 2149.

12. Ai, X.; Wang, X.; Liu, J. M.; Ge, Z. M.; Cheng, T. M.; Li, R. T.; Tetrahedron 2010, 66, 5373.

13. You, L.; Feng, S.; Na, R.; Wang, X.; Bai, D.; Tetrahedron Lett. 2008, 49, 5147.

14. Surendra, K.; Krishnaveni, N. S.; Sridhar, R.; Rao, K. R.; Tetrahedron Lett. 2006, 47, 2125.
15. Ranu, B. C.; Banerjee, S.; Tetrahedron Lett. 2007, 48, 141.

16. Bereska, B.; Czaja, K.; Nowicki, J.; Iłowska, J.; Bereska, A.; Muszyński, M.; Szmatoła, M.; Grabowski, R.; ChemistrySelect 2017, 2, 10020.

17. Yang, L.; Xu, L.-W.; Zhou, W.; Li, L.; Xia, C.-G.; Tetrahedron Lett. 2006, 47, 7723.

18. Mukhopadhyay, C.; Datta, A.; Tapaswi, P. K.; Synth. Commun. 2012, 42, 2453.

19. Dupont, J.; Consorti, C. S.; Suarez, P. A. Z.; Souza, R. F.; Org. Synth. 2002, 79, 236.

20. Zhao, G.; Jiang, T.; Gao, H.; Han, B.; Huang, J.; Sun, D.; Green Chem. 2004, 6, 75.

21. Zhu, H. P.; Yang, F.; Tang, J.; He, M. Y.; Green Chem. 2003, 5 , 38.

22. Gmach, J.; Joachimiak, Ł.; Bazewska, K. M.; Synthesis 2016, 48, 2681.

23. Yeom, C. E.; Kim, M. J.; Kim, B. M.; Tetrahedron 2007, 63, 904.

24. Ying, A. G.; Wang, L. M.; Deng, H. X.; Chen, J. H.; Chen, X. Z.; Yeb, W. D.; Arkivoc 2009, 11, 288.

25. Ying, A. G.; Liu, L.; Wu, G. F.; Chen, G.; Chen, X. Z.; Ye, W. D.; Tetrahedron Lett. 2009, 50, 1653.

26. Ying, A.-G.; Chen, X.-Z.; Wu, C.-L.; Zheng, R.-H.; Liang, H.D.; Ge, C.-H.; Synth. Commun. 2012, 42, 3455.

27. Szánti-Pintér, E.; Maksó, L.; Wouters, J.; Herman, B. E.; Szecsi, M.; Miklee, G.; Kollr, L.; Steroids 2017, 123, 61.

28. Han, F.; Yang, L.; Li, Z.; Xia, C.; Org. Biomol. Chem. 2012, 10, 346.

29. Dunning, T. H.; J. Chem. Phys. 1989, 90, 1007.

30. The PyMOL Molecular Graphics System, version 2.0; Schrödinger, LLC, USA, 2017.

31. Zhao, Y.; Truhlar, D. G.; Theor. Chem. Acc. 2008, 120, 215.

32. Krishnan, R.; Binkley, J. S.; Seeger, R.; Pople, J. A.; J. Chem. Phys. 1980, 72, 650.

33. Shibata, J. H.; J. Chem. Educ. 2012, 89, 1489.

34. Simon, S.; Duran, M.; Dannenberg, J. J.; J. Chem. Phys. 1996, $105,11024$.

35. Roy, S. R.; Chakraborti, A. K.; Org. Lett. 2010, 12, 3866.

Submitted: November 25, 2019

Published online: April 9, 2020 